\title{
OBTAINING TEMPERATURE FIELDS AS A FUNCTION OF EFFICIENCY IN TIG WELDING BY NUMERICAL MODELING
}

\author{
P. B. Guimarães ${ }^{\mathrm{a}, \mathrm{b}}$, \\ P. M. A. Pedrosab, \\ Y. P. Yadavab, \\ A. V. Siqueira Filhob, \\ J. M. A. Barbosa ${ }^{\text {, }}$ \\ and R. A. S. Ferreira ${ }^{b}$ \\ ${ }^{a}$ Instituto Federal de Pernambuco \\ Departamento de Mecânica \\ Cidade Universitária \\ CEP. 50740-540, Recife, Pernambuco, Brasil \\ pabloguimaraes@recife.ifpe.edu.br \\ ${ }^{b}$ Universidade Federal de Pernambuco \\ Departamento de Engenharia Mecânica \\ Cidade Universitária \\ CEP. 50.740-530, Recife, Pernambuco, Brasil \\ ras@ufpe.br

\section{NOMENCLATURE} \\ $a_{f} \quad$ length of the weld pool before the torch, $m$ \\ $a_{r} \quad$ length of the weld pool after the torch, $m$ \\ b semi-width of the weld pool, $\mathrm{m}$ \\ c depth of fusion zone, $\mathrm{m}$ \\ $\mathrm{c}_{\mathrm{p}} \quad$ specific heat at constant pressure, $\mathrm{J} / \mathrm{kg} .{ }^{\circ} \mathrm{C}$ \\ $\mathrm{f}_{\mathrm{f}}$ departments of energy before the torch \\ $f_{r} \quad$ departments of energy after the torch \\ $\mathrm{h} \quad$ convective heat transfer coefficient, $\mathrm{W} \cdot \mathrm{m}^{2} /{ }^{\circ} \mathrm{C}$ \\ $\mathrm{h}_{\mathrm{p}} \quad$ thickness of the plate, $\mathrm{m}$ \\ $\mathrm{K}$ thermal conductivity, W.m $/{ }^{\circ} \mathrm{C}$ \\ $\mathrm{K}_{0} \quad$ modified Bessel function \\ I electrical current, A \\ $\mathrm{U}$ voltage, $\mathrm{V}$ \\ $\mathrm{T}_{0} \quad$ initial temperature, ${ }^{\circ} \mathrm{C}$ \\ $\mathrm{T}$ temperature, ${ }^{\circ} \mathrm{C}$ \\ $v \quad$ welding speed, $\mathrm{m} / \mathrm{s}$
}

\section{ABSTRACT}

The temperature field serves as the basis for predicting levels of residual stress in a welded joint. The aspects related to the mathematical modeling of complex welding procedures were pondered with the FEM: variations in the physical and mechanical properties of the materials as a function of the temperature, the transience and the speed of the welding process, the material phase transformations, the different mechanisms of heat exchange with the environment (convection and radiation), all them associated with a high level of nonlinearity. The heat source used in this analytical model for heat supply was the double ellipsoid model proposed by Goldak (2005), in which a $60 \mathrm{~mm} \times 50 \mathrm{~mm}$ and $3 \mathrm{~mm}$ rectangular ASTM AH36 steel plate was used for the TIG process simulations. It was made a comparison of temperature fields for three different values of process efficiency $(60 \%, 70 \%$ and $80 \%$ ). The results showed many differences in the temperature fields following changes in the levels of residual stresses which will be determined in further studies.

Keywords: Temperature Field, Residual Stress, TIG Welding.

\section{Greek symbols}

$\alpha \quad$ thermal diffusivity, $\mathrm{m}^{2} / \mathrm{s}$

$\varepsilon \quad$ emissivity

$\sigma \quad$ Stefan-Boltzmann's constant, W.m ${ }^{-2} \cdot{ }^{\circ} \mathrm{C}^{-4}$

\section{INTRODUCTION}

The TIG (Tungsten Inert Gas) welding technique begins with the creation and maintainance of the electric arc between a non-consumable tungsten electrode and a base metal (Modenesi et al., 2006; Gonçalves et al., 2006). This welding process was first developed by the aeronautical industry during the World War II to make easier the weld process of light materials such as aluminum and magnesium. After the improvement, TIG became a process of high quality and relatively high cost used in various applications (Marques et al., 2007). In this study, the temperature fields were numerically developed considering three different levels of electrical current in order to obtain the residual stresses of a welded joint subsequently. This numerical model is based on the coupling of different physical phenomena in thermal, mechanical and metallurgical natures, always present in a welding operation. In the $4^{\text {th }}$ decade of the twentieth century, an analytical method was proposed by Rosenthal (1941) to solve the thermal problem, taking into consideration a concentrated heat source (punctual or linear). For the analytical solutions Rosenthal proposed the following simplifying assumptions (Ramanzini et al., 2006 and Goyal et al., 2009): The heat source (punctual, linear) moving at a constant speed along a plate; the physical properties of the medium (part) are constant; heat loss through the surface (convection) are negligible; welding is long enough to reach the quasi-steady state (constant temperature distribution to the observer placed at the heat source) and the phase transformations are negligible. For the modeling of thin plates, the 
temperature distribution is constant for the observer who moves along a linear heat source with constant velocity, as shown in Figure 1.

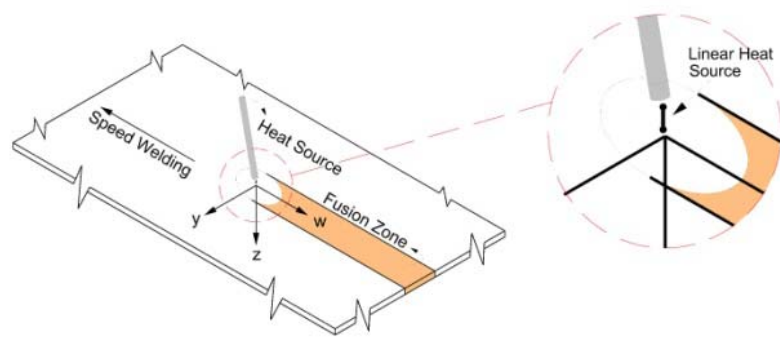

Figure 1. Heat source for linear analysis of twodimensional heat flow.

Considering that there is no flow in the plate thickness direction and shifting the origin of coordinates of the plate for the linear heat source, the heat conduction takes place in the $\mathrm{x}$ and $\mathrm{y}$ directions, featuring a bi-directional flow (Binda et al., 2004; Gonçalves et al., 2006).

$$
T=T_{0}+\frac{P / h_{p}}{2 \pi k} e^{-\frac{v}{2 \alpha} x} K_{0} \cdot \frac{v}{2 \alpha} \cdot \sqrt{x^{2}+y^{2}}
$$

Taking as reference the coordinates, the temperature of a point at a distance $\mathrm{r}(\mathrm{x}, \mathrm{y})$ has a solution given by Equation (1).

where $\alpha$ is the thermal diffusivity, $\mathrm{k}$ is the thermal conductivity, $h$ is the thickness of the plate and $\mathrm{v}$ is the welding speed. According Depradeux (2003), these analytical models are well suited only when the size of the fusion is considered a zone very small as compared with the dimensions of the piece. New analytical solutions have been proposed, in which take into account a heat source distributed (Fassani and Trevisan, 2003). For modeling the heat source proposed by Goldak, conduces to an analytical solutions that is currently the most suitable for TIG processes, where is considered a 3D finite Gaussian over a double ellipsoid, as shown in Figure 2.

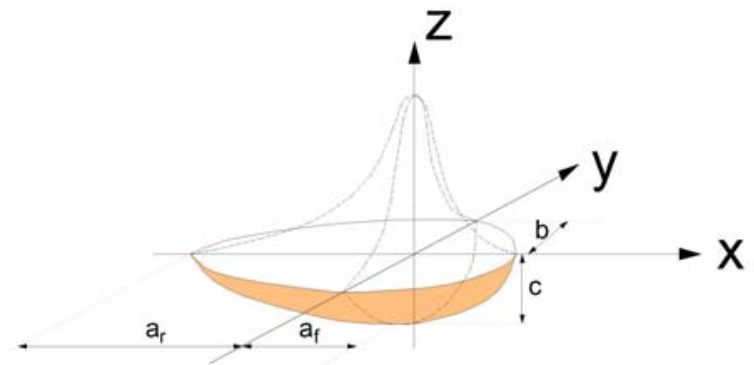

Figure 2. Schematic representation of the double ellipsoid heat source.

$$
\begin{aligned}
& q_{f}(x, y, z)=f_{f} \frac{\eta U I}{a_{f} b c \pi \sqrt{\pi}} \cdot 6 \sqrt{3} \cdot \exp \left(\frac{-3 x^{2}}{a_{f}^{2}}\right) \cdot \exp \left(\frac{-3 y^{2}}{b^{2}}\right) \cdot \exp \left(\frac{-3 z^{2}}{c^{2}}\right)(2) \\
& q_{r}(x, y, z)=f_{r} \frac{\eta U I}{a_{f} b c \pi \sqrt{\pi}} \cdot 6 \sqrt{3} \cdot \exp \left(\frac{-3 x^{2}}{a_{r}^{2}}\right) \cdot \exp \left(\frac{-3 y^{2}}{b^{2}}\right) \cdot \exp \left(\frac{-3 z^{2}}{c^{2}}\right)(3)
\end{aligned}
$$

This source is defined analytically by Equation (2) and Equation (3) (Goldak and Chakravarti, 1984; Goldak and Akhlaghi, 2005).

Where $\mathrm{q}_{\mathrm{f}}$ and $\mathrm{q}_{\mathrm{r}}$ are the volumetric energy distributions before and after the torch $\left[\mathrm{w} / \mathrm{m}^{3}\right] ; \mathrm{f}_{\mathrm{f}}$ and $\mathrm{f}_{\mathrm{r}}$ are the departments of energy before and after the torch; $\mathrm{a}_{\mathrm{f}}$ and $\mathrm{a}_{\mathrm{r}}$ are the length of the weld pool before and after the torch $[\mathrm{m}] ; \mathrm{b}$ is the semi-width of the weld pool [m] and $\mathrm{c}$ is the depth of fusion zone [m] as shown in Figure 2.

The $U$ and I parameters are linked directly to the welding procedure, while $\mathrm{b}$ and $\mathrm{c}$ are the geometrical parameters of the source, which may be determined by metallographic examination.

$$
\begin{gathered}
f_{f}+f_{r}=2 \\
f_{f}=\frac{2 \cdot a_{f}}{a_{f}+a_{r}} \\
f r=\frac{2 \cdot a_{r}}{a_{f}+a_{r}}
\end{gathered}
$$

The other parameters $a_{f}, a_{r}, f_{f}$ and $f_{r}$, are obtained by helping of parameters $b$ and $c$ which are related in the bibliography, as shown on Equations (4), (5) and (6) (Gery et al., 2005; Goldak and Akhlaghi, 2005).

\section{EXPERIMENTS}

For the simulation of residual stresses, a $60 \mathrm{~mm}$ $x$ 50mm and $3 \mathrm{~mm}$ rectangular ASTM AH36 steel plate was used, considering the use of a TIG (tungsten inert gas) in the welding process. Table 1 shows the chemical composition of the alloy.

Table 1. Chemical composition of the sample of ASTM AH36.

\begin{tabular}{|c|c|c|c|c|c|}
\hline $\mathbf{C}$ & $\mathbf{C r}$ & $\mathbf{M n}$ & $\mathbf{N i}$ & $\mathbf{S i}$ & $\mathbf{V}$ \\
\hline 0.130 & 0.026 & 1.418 & 0.012 & 0.346 & 0.056 \\
\hline $\mathbf{A l}$ & $\mathbf{C u}$ & $\mathbf{S}$ & $\mathbf{P}$ & $\mathbf{S n}$ & $\mathbf{N b}$ \\
\hline 0.028 & 0.015 & 0.007 & 0.023 & 0.002 & 0.020 \\
\hline
\end{tabular}

Numerical simulations were performed with a software program (Abaqus) based on the finite element method (FEM). The board was divided into elements type DC3D8 sum to a total of 18788 elements. This mesh presented more refinement in the fusion zone and in the heat affected zone (HAZ), because those were the areas where the most important phenomena in the welding process 
occurred. This mesh refinement is shown in Figure 3 and in Table 2.

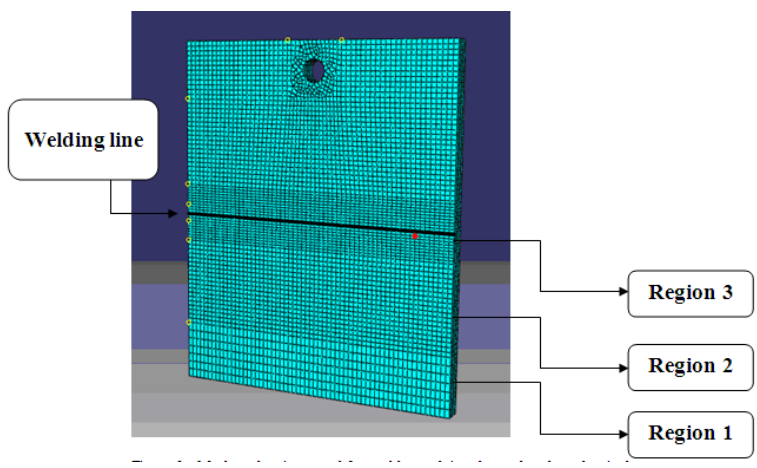

Figure 3. Mesh and regions used for problem solving thermal and mechanical.

Table 2. Elements that make up the mesh for the FEM calculation.

\begin{tabular}{|c|c|c|c|}
\hline & Region 1 & Region 2 & Region 3 \\
\hline $\begin{array}{c}\text { Number } \\
\text { of } \\
\text { Elements }\end{array}$ & 4336 & 9272 & 4880 \\
\hline
\end{tabular}

These elements are continuous - 3D of linear formulation and each one of them contains 8 nodes (Figure 4). For all elements, edges along the $0,75 \mathrm{~mm}$ thick were always used, remaining four elements along the thickness of the plate.

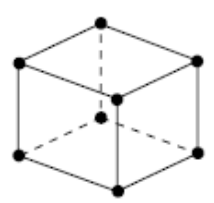

Figure 4. Element DC3D8 - 8 nodes and linear formulation (Hibbit et al., 2007).

$\frac{\partial}{\partial x}\left(K_{T} \frac{\partial T}{\partial x}\right)+\frac{\partial}{\partial y}\left(K_{T} \frac{\partial T}{\partial y}\right)+\frac{\partial}{\partial z}\left(K_{T} \frac{\partial T}{\partial z}\right)+\dot{q}=\rho c \frac{\partial T}{\partial t}$

The solution of the thermal problem is given by Equation (7).

For the thermal boundary conditions, the exchange of convection and radiation was considered during the welding process. These boundary conditions were imported to the model. Five sides of the plate were welded, except the lower surface, which rested on the table during the welding operation.

$$
\begin{gathered}
q_{c}=h\left(T-T_{0}\right) \\
q_{R}=\sigma \cdot \varepsilon \cdot\left(T^{4}-T_{\infty}^{4}\right)
\end{gathered}
$$

Heat exchange by convection and radiation was expressed by Eq. (8) (Newton's law) and Eq. (9) (Stefan Boltzmann's law), respectively.

Where $\mathrm{h}$ is the convection coefficient, $\sigma$ is the Stefan-Boltzmann's constant and $\varepsilon$ represents emissivity. Literature values were used to model heat exchange and the assumed convection around the board. The ambient temperature considered was $25^{\circ}$ $\mathrm{C}$ and emissivity 0.7. The values used for the convection coefficient $(h)$, specific heat $\left(\mathrm{C}_{\mathrm{p}}\right)$ and thermal conductivity $(k)$ are shown in Figure 5 (Tsirkas et al. 2003) as a function of temperature.

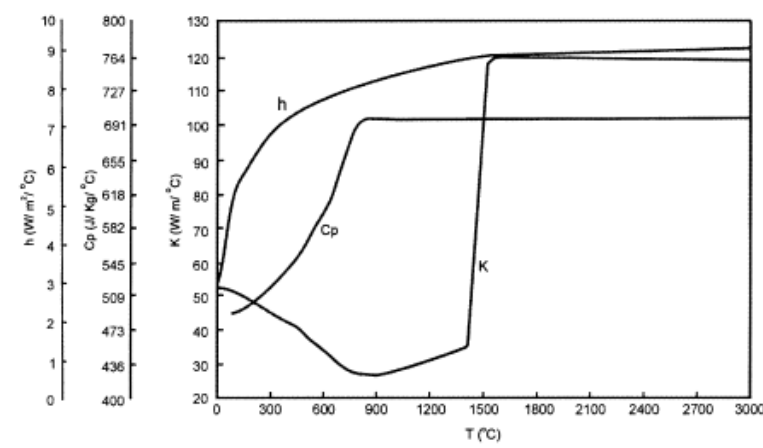

Figure 5. Variation of material properties as a function of temperature (tsirkas et al., 2003).

The source used in this study was the double ellipsoid model proposed by Goldak, shown in Figure 2. The geometric parameters $a_{f}, a_{r}, b, c$ and the energy parameters $f_{f}$ and $f_{r}$ were obtained with the support of the relationships found in references suggested by Gery et al (2005) and Goldak et al. (2005) (Table 3). During the modeling, a FORTRAN DFLUX subroutine (Hibbit et al. 2007) was developed to displace the heat source. This function determines the torch position versus time, and calculates the heat input in all points of the board. Only one mechanical boundary condition was established because the plate was attached through a $4 \mathrm{~mm}$ diameter hole, as shown in Figure 2 (Danis et al. 2008).

Table 3. Geometrical parameters and energy from the heat source (Goldak \& Akhlaghi, 2005; Danis, 2008).

\begin{tabular}{|c|c|}
\hline Parameter & Value \\
\hline $\mathrm{a}_{\mathrm{f}}$ & $0.0025 \mathrm{~m}$ \\
\hline $\mathrm{a}_{\mathrm{r}}$ & $0.0015 \mathrm{~m}$ \\
\hline $\mathrm{b}$ & $0.0025 \mathrm{~m}$ \\
\hline $\mathrm{c}$ & $0.003 \mathrm{~m}$ \\
\hline $\mathrm{f}_{\mathrm{f}}$ & 0.6 \\
\hline $\mathrm{f}_{\mathrm{r}}$ & 1.4 \\
\hline
\end{tabular}

For the numerical simulations performed, in this study the value of the voltage and electrical current were kept constant and equal to $14 \mathrm{~V}$ and $152 \mathrm{~A}$ respectively. The variations in efficiency source were applied, as shown in Table 4. 
Table 4. Parameters of heat input used in the numerical simulation.

\begin{tabular}{|c|c|c|c|}
\hline $\begin{array}{c}\text { Current } \\
\text { (A) }\end{array}$ & $\begin{array}{c}\text { Voltage } \\
\text { (V) }\end{array}$ & $\begin{array}{c}\text { Efficiency } \\
\text { (\%) }\end{array}$ & $\begin{array}{c}\text { Speed } \\
\text { (m/s) }\end{array}$ \\
\hline 152 & 14 & 60 & 0.001 \\
\hline 152 & 14 & 70 & 0.001 \\
\hline 152 & 14 & 80 & 0.001 \\
\hline
\end{tabular}

\section{RESULTS AND DISCUSSION}

The virtual welding lasted 50s. The evolution of temperature field for efficiency source of $60 \%, 70 \%$ and $80 \%$ are shown in the Figures 6,7 and 8 respectively.

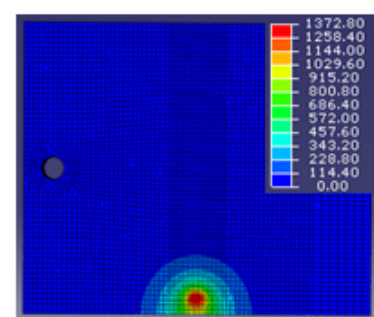

(a)

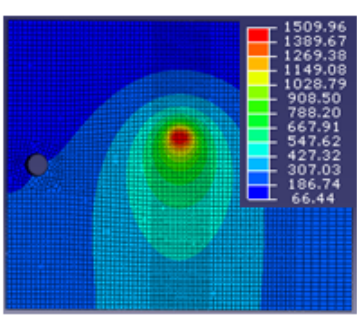

(c)

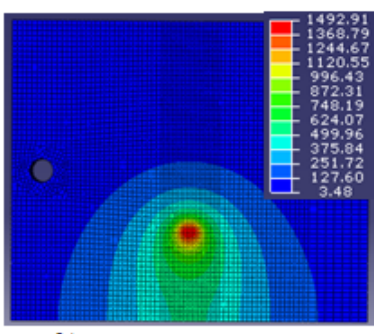

(b)

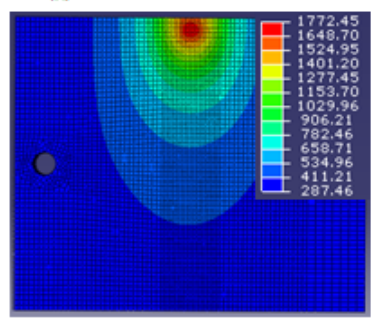

(d)
Figure 6. Evolution of the field of temperature $\left[{ }^{\circ} \mathrm{C}\right]$ for efficiency source of $60 \%$ as a function of the welding times (a) $5 \mathrm{~s}$, (b) $15 \mathrm{~s}$, (c) $30 \mathrm{~s}$ and (d) $50 \mathrm{~s}$.

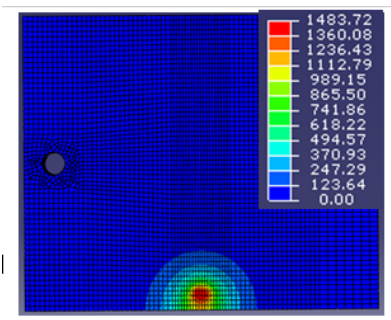

(a)

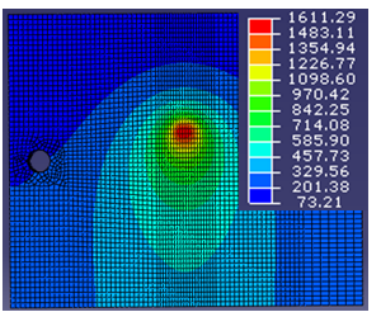

(c)

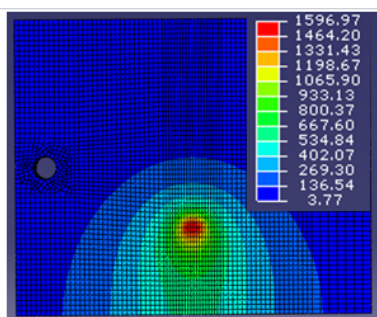

(b)

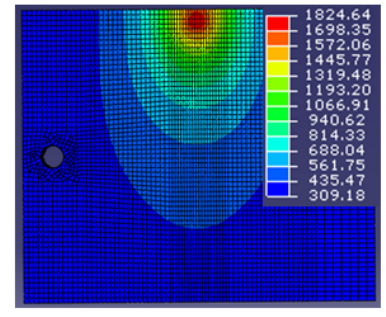

(d)
Figure 7. Evolution of the temperature field $\left[{ }^{\circ} \mathrm{C}\right]$ for efficiency source of $70 \%$ as a function of the welding times (a) $5 \mathrm{~s}$, (b) $15 \mathrm{~s}$, (c) $30 \mathrm{~s}$ and (d) $50 \mathrm{~s}$.

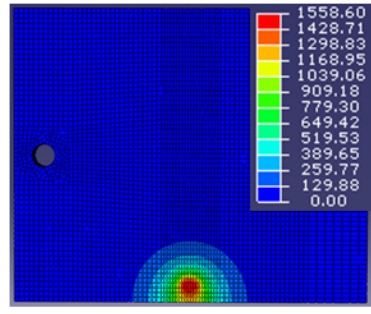

(a)

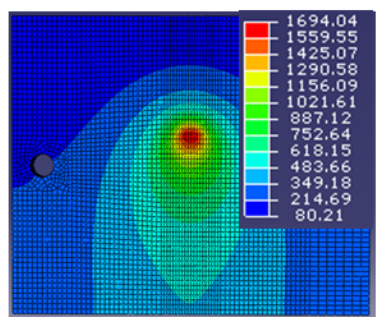

(c)

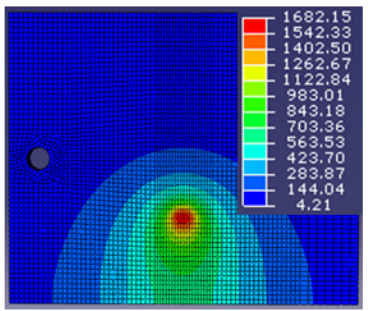

(b)

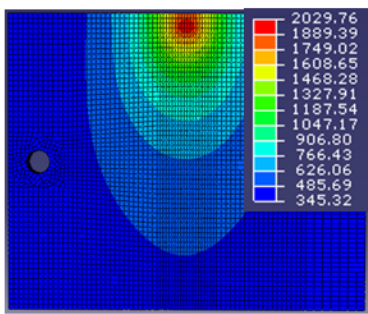

(d)
Figure 8. Evolution of the temperature field $\left[{ }^{\circ} \mathrm{C}\right]$ for efficiency source of $80 \%$ as a function of the welding times (a) $5 \mathrm{~s}$, (b) $15 \mathrm{~s}$, (c) $30 \mathrm{~s}$ and (d) $50 \mathrm{~s}$.

The evolution of the temperature field is influenced by the parameters of the heat source and the heat input welding. The contours of this field are directly influenced by the welding speed and the physical properties of the material. For simulations, a welding speed of $1 \mathrm{~mm} / \mathrm{s}$ was used. Under these conditions (Figures 6,7 and 8), the Heat Affected Zone (HAZ) is higher for the current of $162 \mathrm{~A}$, due to the increase in heat input. If the speed of welding increases the contours of the isotherms tend to stretch more towards the opposite direction to welding, thus affecting a smaller area (Chon and Chin, 1993), however the welding speed in this work was kept constant. In this model the temperature remains nearly constant over the thickness, according to the problem solution for thin plate proposed by Rosenthal (1941).

The maximum temperature achieved for the welding efficiency of $60 \%$ was $1772^{\circ} \mathrm{C}$, for the welding efficiency of $70 \%$ was $1824^{\circ} \mathrm{C}$ and for the efficiency of welding of $60 \%$ was $2029^{\circ} \mathrm{C}$.

In literature, models that do not take into account the phase transformations $(\gamma-\alpha)$ of material can be easily found, but they present poor accuracy in results concerning the temperature field. In this study, phase transformations were considered but these simulated results are in accordance with experimental results (Guimarães, 2010).

\section{CONCLUSIONS}

The determination of the temperature field in welding produced by TIG can be simulated by using the Abaqus code in which both thermal and mechanical effects can be considered as well. Considering the phase transformation $(\gamma-\alpha)$ during 
virtual welding, the model presented consistent results under the experiment.

The determination of the temperature field can be used either for the optimization of welding procedures in future works or in reducing the levels of residual stress in different industrial range, such as in the petrochemical and shipbuilding industries.

\section{ACKNOWLEDGEMENTS}

We would like to thank FACEPE (Pernambuco State Foundation for Science and Technology) for the financial support to this study.

\section{REFERENCES}

Binda, B., Capello, E. and Previtali, B., 2004, A semi-empirical model of the temperature field in the AISI 304 laser, welding Journal of Materials Processing Technology. Vol. 155, pp. 1235-1241.

Chon, L. T. and Chin, M. T., 1993, Heat Flow in Fusion Welding - Parametric Effects, ASM HANDBOOK. Vol. 6, pp. 46-53.

Danis, P. Y., 2008, Étude de la soudabilité d'um superalliage base nickel fortement charge em éléments durcissants titane et aluminium: l'inconel 738, Doctoral Thesis, L'Université Bordeaux 1, France.

Depradeux, L. and Jullien, J. F., 2003, Experimental and numerical simulation of thermomechanical phenomena during a TIG welding process, In: International Conference on Thermal Process Modelling and Computer Simulation. Nancy, France, pp. 697-704.

Fassani, R. N. S. and Trevisan, O. V., 2003, Analytical Modeling of Multipass Welding Process with Distributed Heat Source, Journal of the Braz. Soc. of Mech. Sci. \& Eng. Vol. XXV, No. 3, pp. 302305.

Gery, D., Long, H. and Maropoulos, P., 2005, Effects of welding speed, energy input and heat source distribution on temperature variations in butt joint welding, Journal of Materials Processing Technology. Vol. 167, pp. 393-40.

Goldak, J. A. and Akhlaghi, M., 2005, Computational Welding Mechanics, Spring, New York.

Gonçalves, C. V., Vilarinho, L. O., Scotti, A. and Guimarães, G., 2006, Estimation of heat source and thermal efficiency in GTAW process by using inverse techniques, Journal of Materials Processing Technology . Vol. 172, pp. 42-51.

Goyal, V. K., Ghosh, P. K. and Saini, J. S., 2009, Analytical studies on thermal behaviour and geometry of weld pool in pulsed current gas metal arc welding, Journal of materials processing technology. Vol. 209, pp.1318-1336.
Guimarães, P. B., 2010, Estudo do Campo de Temperatura Obtido Numericamente para Posterior Determinação das Tensões Residuais em uma Liga de Aço ASTM AH36, Doctoral Thesis, Universidade Federal de Pernambuco, Brazil. (in Portuguese)

Hibbit, Karlsson \& Sorenson Inc., 2007, Abaqus User Subroutines Reference Manual version 6.7, USA.

Hibbit, Karlsson \& Sorenson Inc., 2007, Abaqus Getting Started with Abaqus - Interactive Edition version 6.7, USA.

Marques, P. V., Modenesi, P. J., Bracarense, A.Q., 2007, Soldagem: Fundamentos e Tecnologia. Ed. UFMG, Belo Horizonte, Brazil. (in Portuguese)

Modenesi, P. J., Marques, P. V. and Santos, D. B., 2006, Introdução à Metalurgia da Soldagem. Universidade Federal de Minas Gerais. DEM, Belo Horizonte, Brazil. (in Portuguese)

Ramanzini, R. and Paucar Casas, W. J., 2006, Distribuição do Campo de Temperaturas num Protótipo Virtual de Junta Soldada Multipasse, in: $17^{\circ}$ CBECiMat - Congresso Brasileiro de Engenharia e Ciência dos Materiais. PR, Brazil. pp. 7791-7800. (in Portuguese)

Rosenthal, D., 1941, Mathematical theory of heat distribution during welding and cutting, Weld. J. Vol. 20, pp. 220-234.

Tsirkas, S. A., Papanikos, P. and Kermanidis, T.H., 2003, Numerical Simulation of the Laser Welding Process in butt-joint specimens, Journal of Materials Processing Technology. Vol. 134, pp. 5969.

\footnotetext{
Received: July 30, 2011

Revised: August 30, 2011

Accepted: September 30, 2011
} 